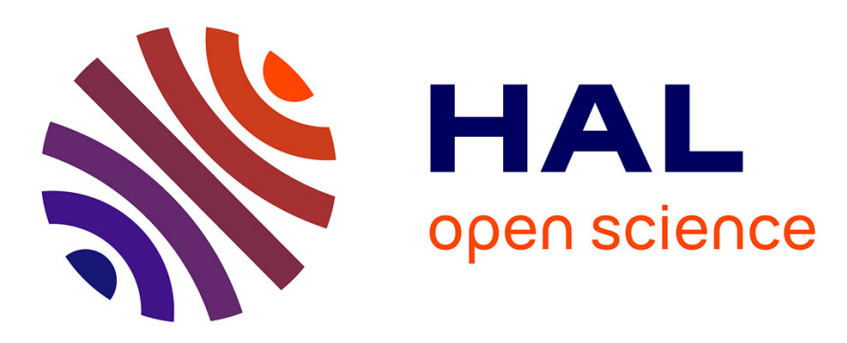

\title{
Fracture toughness of glasses and hydroxyapatite: a comparative study of 7 methods by using Vickers indenter
}

Isabel Hervas, Alex Montagne, Adrien van Gorp, M. Bentoumi, Anthony Thuault, Alain Iost

\section{To cite this version:}

Isabel Hervas, Alex Montagne, Adrien van Gorp, M. Bentoumi, Anthony Thuault, et al.. Fracture toughness of glasses and hydroxyapatite: a comparative study of 7 methods by using Vickers indenter. Ceramics International, 2016, 42 (11), pp.12740-12750. 10.1016/j.ceramint.2016.05.030 . hal-01337280

\section{HAL Id: hal-01337280 \\ https://hal.science/hal-01337280}

Submitted on 24 Jun 2016

HAL is a multi-disciplinary open access archive for the deposit and dissemination of scientific research documents, whether they are published or not. The documents may come from teaching and research institutions in France or abroad, or from public or private research centers.
L'archive ouverte pluridisciplinaire HAL, est destinée au dépôt et à la diffusion de documents scientifiques de niveau recherche, publiés ou non, émanant des établissements d'enseignement et de recherche français ou étrangers, des laboratoires publics ou privés. 


\title{
Fracture toughness of glasses and hydroxyapatite: A comparative study of 7 methods by using Vickers indenter
}

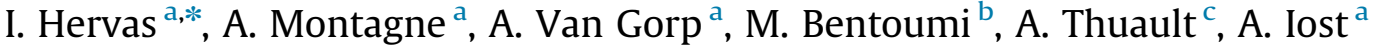 \\ ${ }^{a}$ Arts \& Métiers ParisTech, Mechanics Surfaces and Materials Processing (MSMP), 8, boulevard Louis XIV, 59046 Lille, France \\ ${ }^{\mathrm{b}}$ Applied Optics Laboratory, Institute of Optics and Precision Mechanics, Ferhat Abbas University Setif 1, Algeria \\ ${ }^{\mathrm{c}}$ Laboratory of Ceramic Materials and Associated Processes (LMCPA), University of Valenciennes and Hainaut Cambresis (UVHC), Boulevard Charles de \\ Gaulle, 59600 Maubeuge, France
}

Keywords:

Indentation

Fracture toughness

Brittle fracture

Hydroxyapatite

Optical glasses

\begin{abstract}
A B S T R A C T
Numerous methods have been proposed to estimate the indentation fracture toughness Kic for brittle materials. These methods generally uses formulæ established from empirical correlations between critical applied force, or average crack length, and classical fracture mechanics tests. This study compares several models of fracture toughness calculation obtained by using Vickers indenters. Two optical glasses (Crown and Flint), one vitroceramic (Zerodur) and one ceramic (hydroxyapatite) are tested. Fracture toughness and hardness are obtained by using instrumented Vickers indentation at micrometer scale. Young's moduli are obtained by instrumented Berkovich indentation at nanometer scale. Fracture toughness is calculated with models involving crack length measurements, and by models free of crack length measurements by considering critical force, chipping, pop-in. Finally, method based on the cracking energy, commonly employed for coated materials is also used.

The aim of this work is to compare seven methods, which enable the facture toughness determination, on four brittle materials. To do so, it was necessary to determine some specific constant in the case of Vickers tip use.

On the one hand, results show that methods using crack length, critical force, edge chipping or pop-in lead to comparable results, and the advantages and drawbacks are highlighted. On the other hand, the indentation energy method leads to underestimated results of about $20 \%$.
\end{abstract}

\section{Introduction}

Optical devices miniaturization as well as the synthesis and shaping of new materials require high-performance characterization techniques, which are capable of estimating the mechanical properties such as fracture toughness for all pieces geometry [1]. Furthermore thinning down of optical glasses is mainly done by grinding and polishing, mechanisms which involve hardness and chip formation by scratching. Thus a good knowledge of toughness and hardness of materials is required to determine material loss during abrasion [2,3].

The fracture toughness $K c$ is defined as the resistance offered by a material to the sudden propagation of cracks [3]. In 1892, Larmor [4] determines the influence of defects and porosity on the mechanical resistance of materials. Later Griffith [5] takes into account the existence and the geometry of defects on the material's resistance fracture of brittle materials and develops the

\footnotetext{
* Corresponding author.

E-mail address: isabel.hervas@ensam.eu (I. Hervas).
}

fracture mechanics theory. This theory is then adapted to ductile materials by Irwin [6]. The fracture toughness of materials expressed as the stress intensity factor is considered as a key parameter for predicting the rupture of materials.

Fracture toughness is generally obtained by normalized tensile or bending tests using standardized samples [7-9]. When the sample geometry is unsuitable with tensile or bending tests, indentation test is the only convenient alternative to measure $K c$. In the following, most representative indentation technics using sharp indenters are detailed [10].

\subsection{Methods that requires crack length measurement}

Palmqvist [11] was the first one to use Vickers indentation test to determine a parameter related to fracture toughness. This author proposes a relationship between $K c$ and the work required to nucleate cracks. When a critical force is reached, the average crack length $(c)$ is directly linked to the applied force $(P)$ [11]. Then, numerous studies have proposed a relationship between $P$ and $c$ $[12,13]$. Fig. 1(a) shows an imprint with a half diagonal $a$ and half crack length $c$. 

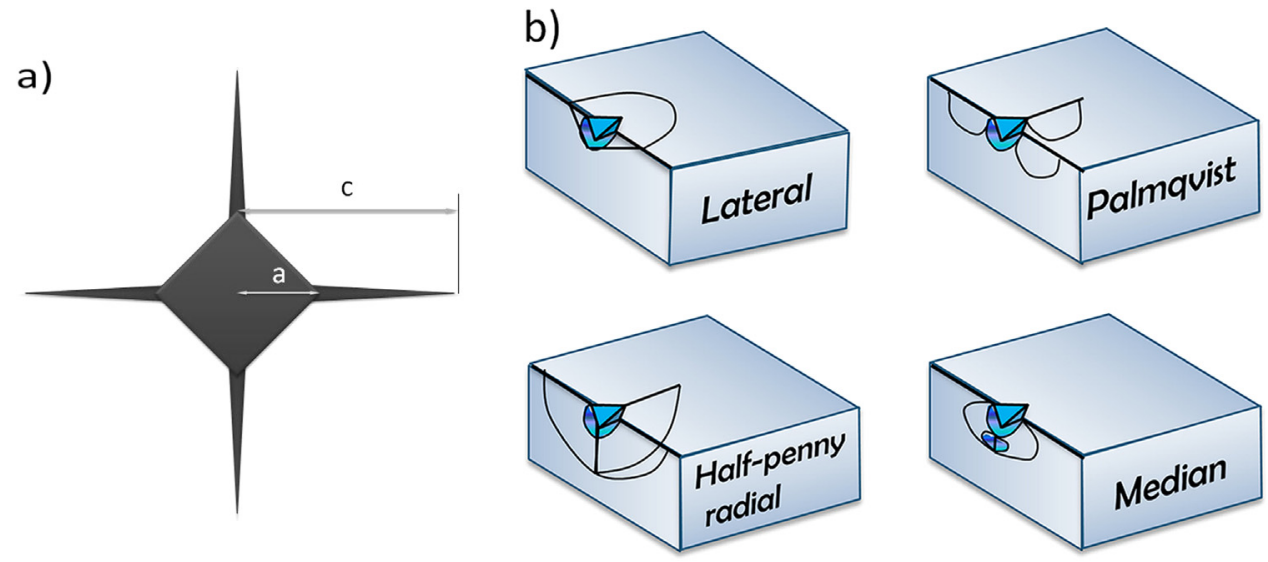

Fig. 1. (a) Residual imprint with a half diagonal "a" and half crack length "c" and (b) different types of cracks.

As shown on Fig. 1(b), the cracks shape is related to the indenter shape and to the nature of the material. They can be of several types: Palmqvist, lateral, median or Half Penny formed from median crack after unloading the sample [14].

\subsubsection{Anstis usual method (Eq. (1))}

Nowadays the mainly used equation to calculate Kic is this proposed by Anstis et al. in 1981 [15,16]. These authors compared results from indentation tests and fracture mechanic methods. They empirically propose an equation, based on results obtained for 16 different materials with fracture toughness ranging from 0.74 to $12 \mathrm{MPa} \mathrm{m}^{1 / 2}$ (Eq. (1)):

$K_{i c}=\chi\left(\frac{E}{H_{V}}\right)^{\frac{1}{2}} \frac{P}{c^{\frac{3}{2}}}$

with $\chi$ a dimensionless constant depending on the crack geometry and on the shape of the indenter $[17,18], H_{V}$ the Vickers hardness and $E$ the elastic modulus in MPa. For a Vickers indenter and a Half Penny type crack, the $\chi$ constant is equal to $0.016 \pm 0.004$. However, this equation implies an uncertainty of $\pm 25 \%$ in the determination of fracture toughness by indentation. Moreover, to use this equation, cracks should be long enough (i.e. $c \geq 2 a$ ) [19].

Gong [20] ascribes a part of this uncertainty to the hardness changes occurring with load increase. On the contrary, he shows that $a^{2} / c^{-3 / 2}$ ratio is load independent. Thus, he replaces the load by the half diagonal of the imprint, thus Eq. (1) becomes:

$K_{i c}=0.046\left(\frac{E}{H}\right)^{\frac{1}{2}} \frac{a^{2}}{c^{\frac{3}{2}}}$

Although this equation presents lower uncertainty, Eq. (1) from Anstis et al. is still the most used one.

\subsubsection{Method using Wt/We ratio (Eq. (4))}

Numerous studies show the link between total and elastic deformation energies ( $W_{t}$ and $W_{e}$ respectively), reduced elastic modulus $\left(E_{r}=E /\left(1-\nu^{2}\right)\right)$ and hardness [21-23] (Eq. (3)):

$\frac{W_{e}}{W_{t}}=k^{-1} \frac{H}{E_{r}}$

$W_{t}$ is the area below the load-displacement curve and $W_{e}$ the area below the unloading curve which corresponds to the elastic deformation, $k$ is a dimensionless constant. The energy $W_{t}$ is the total of elastic and plastic deformation ( $W_{e}$ and $W_{p}$ respectively) (Fig. 2). As suggested by Zhang [24], the major advantage of this method is the use of experimental parameters, very convenient to determine when using instrumented indentation. The fracture

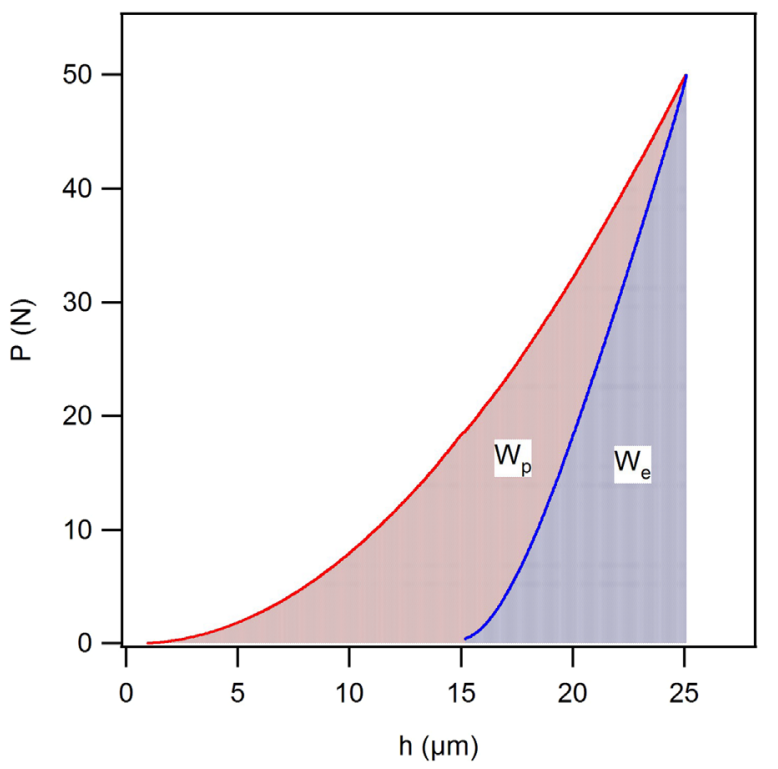

Fig. 2. Definition of elastic $\left(W_{e}\right)$ and plastic $\left(W_{P}\right)$ deformation energy on load-depth curve for Flint glass.

toughness obtained via Eq. (3) does not take into account the hardness evolution with load.

Substituting Eq. (3) in Eq. (2), the Anstis' formulæ becomes:

$K_{i c}=\lambda\left(\frac{W_{t}}{W_{e}}\right)^{\frac{1}{2}} \frac{P}{c^{\frac{3}{2}}}$

The constant $\lambda=\left(1-\nu^{2}\right) \chi k^{-1 / 2}$ is close to 0.0690 for cube corner tip [24] and to 0.0498 for Vickers tip [25].

\subsection{Methods that do not require the measurement of crack length}

The main issue of previous methods is the accurate determination of average crack length. These measurements are tedious and prone to wide uncertainties due to surface preparation or crack length evolution, especially for glasses in moist environment $[26,27]$. Consequently methods without crack length determination have been developed.

\subsubsection{Critical load method (Eq. (5))}

The critical load $\left(P_{c}\right)$ is the minimum load required to initiate a crack in the material. This load is directly linked to fracture toughness [12]. Lawn and Evans [28] propose to calculate $K_{c}$ with Eq. (5): 

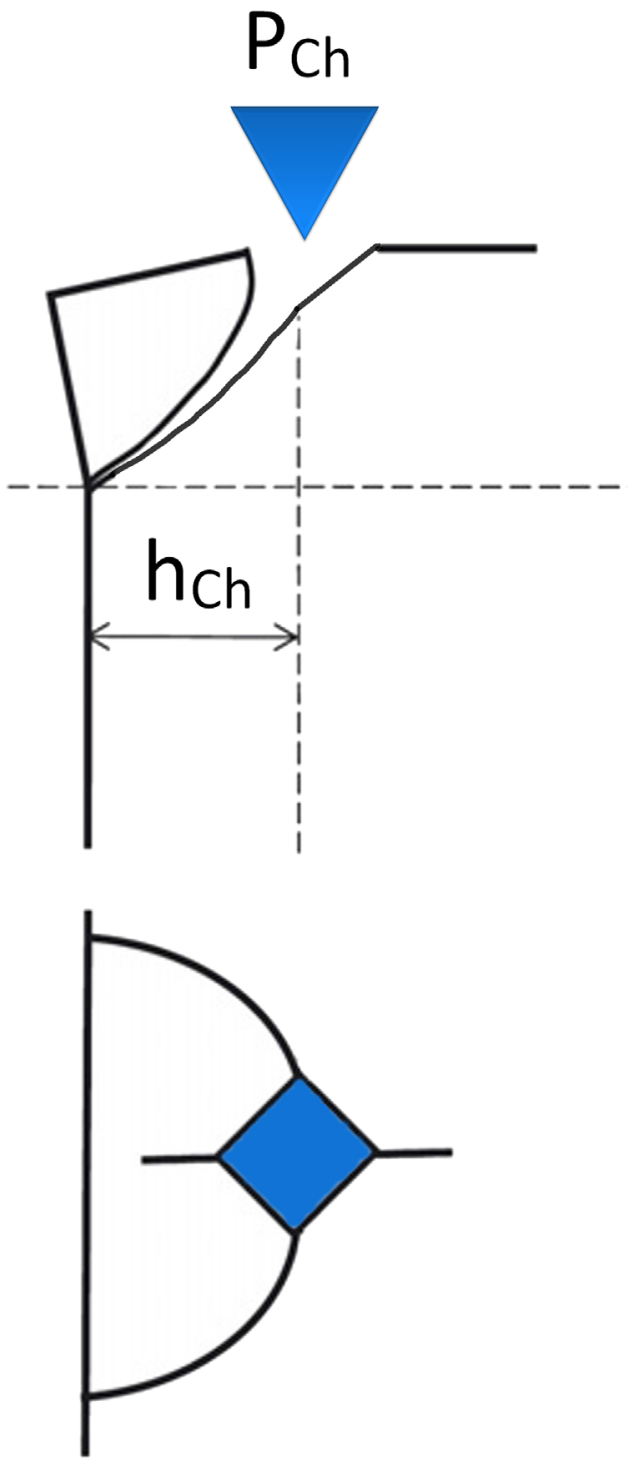

Fig. 3. Schematic representation of the chipping induced by indentation.

$K_{i c}=\left(\frac{1}{\beta} \frac{P_{c}}{H^{3}}\right)^{1 / 4}$

where $\beta$ is a constant equal to $2.210^{4}, P_{c}$ in $\mathrm{N}$, hardness $H$ in GPa

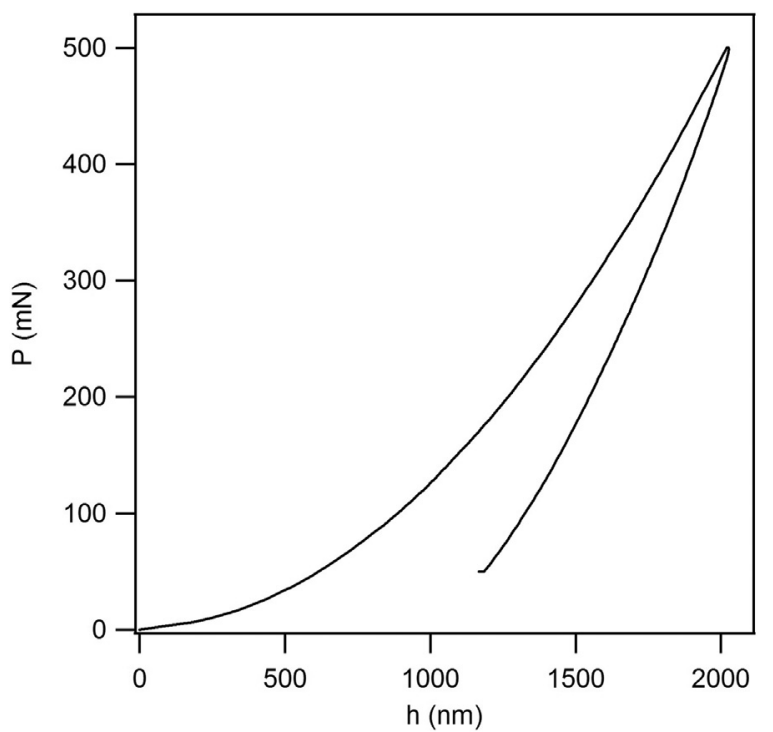

Fig. 5. Indentation curve for a Zerodur glass with a Berkovich indenter (500 mN).

Table 1

Young's modulus and Poisson ratio of glasses and hydroxyapatite.

\begin{tabular}{lllll}
\hline & Crown & Flint & HAP & Zerodur \\
\hline$\nu$ [Réf.] & $0.2[46]$ & $0.2[46,47]$ & $0.25[42,43]$ & $0.25[44,45]$ \\
E(GPa) & 87 & 74 & 125 & 86 \\
E(GPa) [Réf.] & $96[46]$ & $69-100[46,47]$ & $110[42,43]$ & $91[44,45]$ \\
\hline
\end{tabular}

and $K_{i c}$ in MPa m ${ }^{-1 / 2}$. The determination of the critical load can be done by acoustic emission measurements or by presence of bursts on the loading curve.

\subsubsection{Edge chipping method (Eq. (6))}

The edge chipping method consists in an indentation test performed close to the sample edge $\left(h_{c h}\right)$. The critical load $\left(P_{c h}\right)$ needed to create the chip is also measured (Fig. 3). Numerous studies show a linear relationship between the critical chipping load and the distance from the edge to the power $3 / 2$. This ratio is verified for many indenters' geometries [29-31]. Then, Chai and Lawn [32] compared this method to the classical one (Eq. (1)) and get Eq. (6):$$
K_{i c}=\frac{1}{\gamma} \frac{P_{C h}}{h_{C h} \frac{3}{2}}
$$
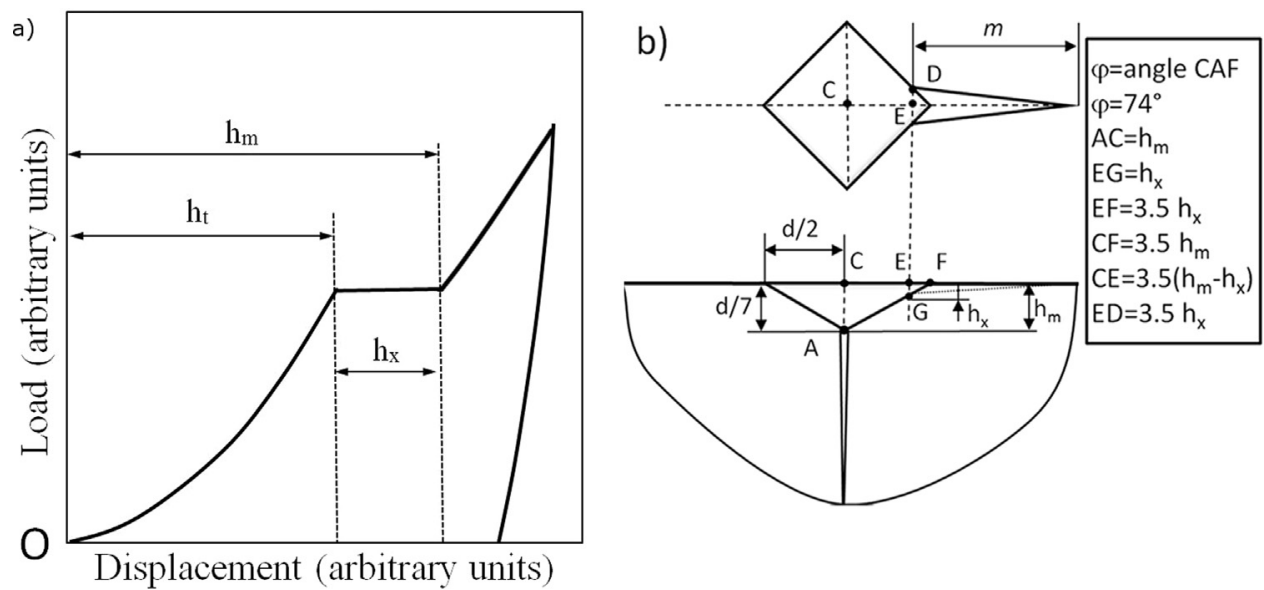

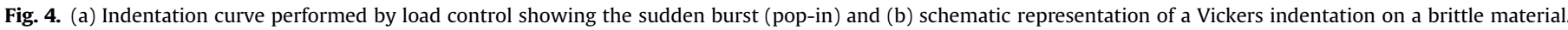




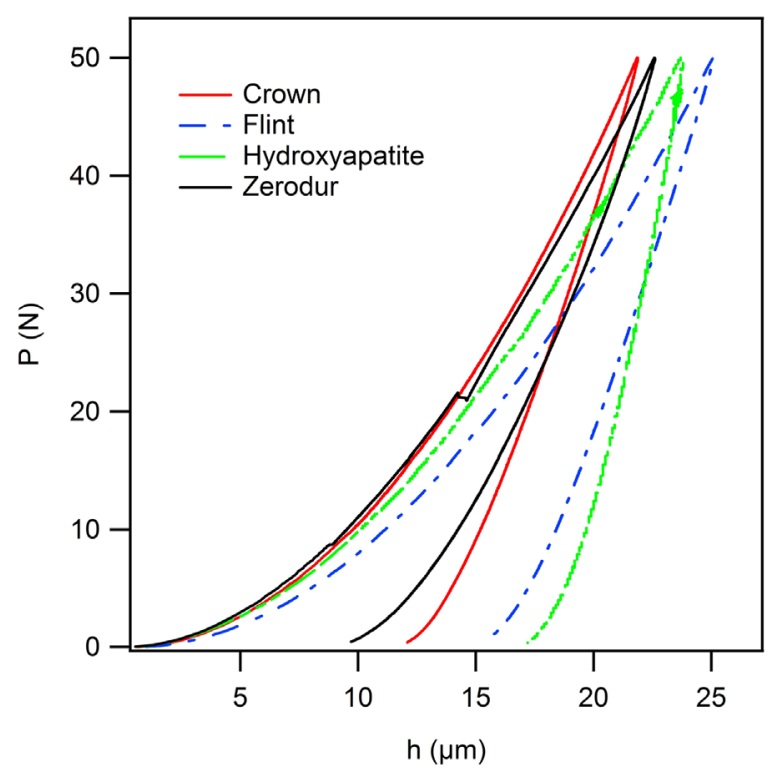

Fig. 6. Instrumented indentation curves for a maximum force of $50 \mathrm{~N}$.

where the constant $\gamma$, equal to $9.3 \pm 1.3$ for a Vickers indenter, is obtained by comparison between indentations tests and classical fracture mechanic tests.

\subsubsection{Pop-in method}

During indentation test, some materials show a pop-in. If the test is performed by using load control mode, the pop-in corresponds to a sudden penetration of the indenter at a constant load

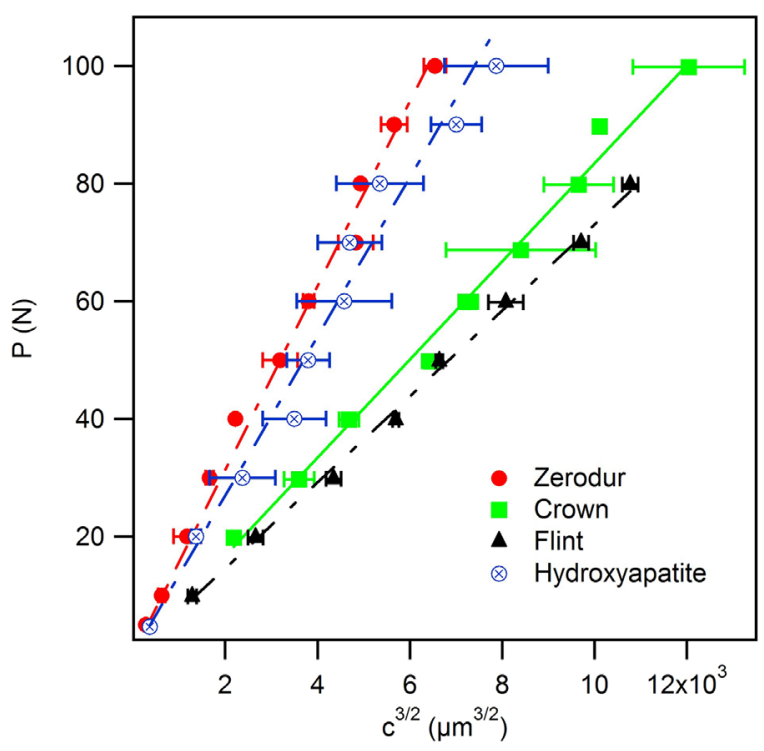

Fig. 8. Influence of the indentation force on the crack length for different materials (Vickers indenter, three tests per load).

(Fig. 4(a)). When cracks appear, the opening of the crack at halflength $\left(\delta_{0}\right)$ is given by:

$\delta_{0}=\frac{8 p m}{\pi E_{r}} D(\gamma)$

with $p$ the pressure at the crack center, $m$ is the radius of the crack, $E_{r}$ the reduced elastic modulus and $D(\gamma)$ a constant ranged
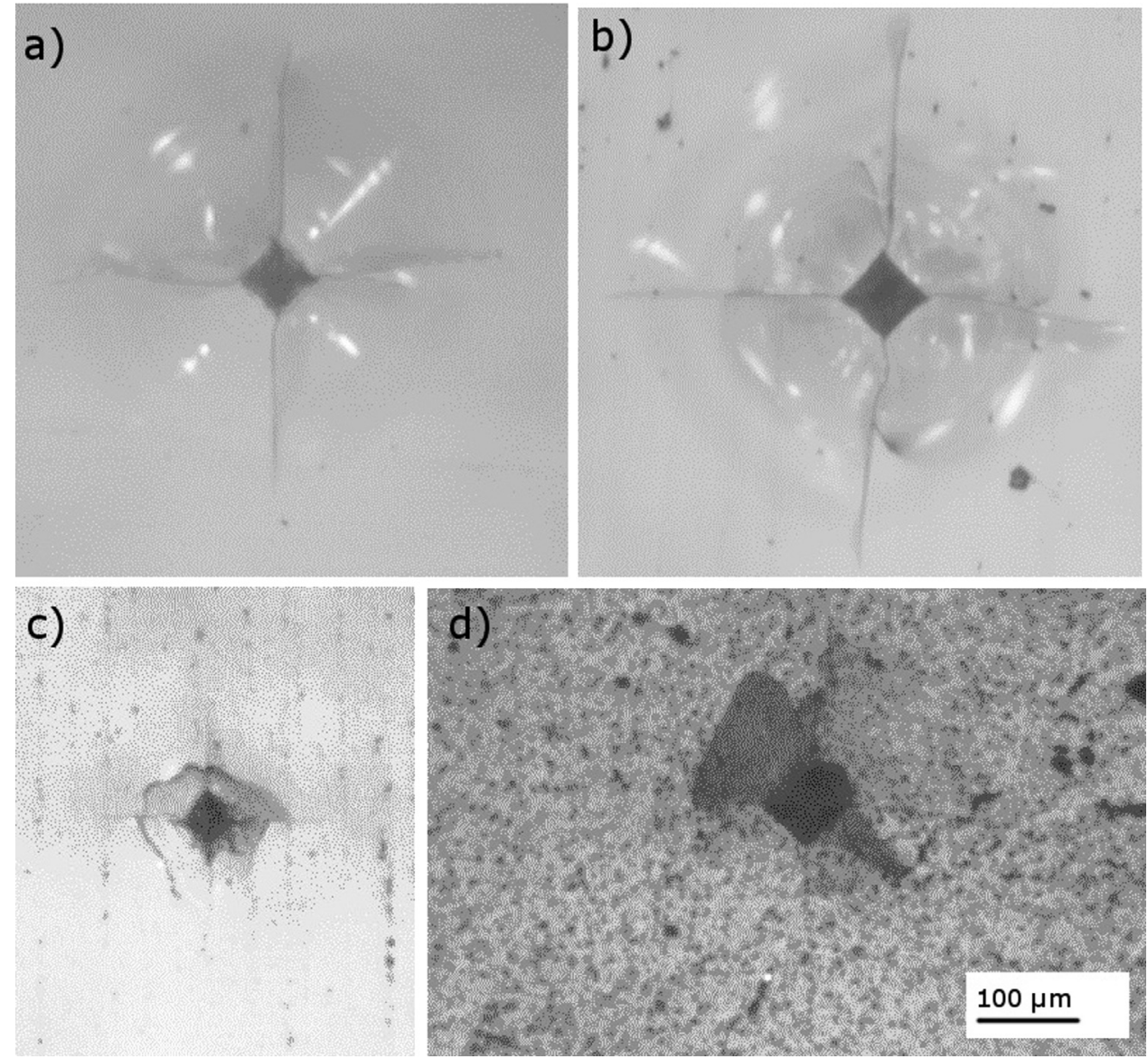

Fig. 7. Vickers indentation of: (a) Crown, (b) Flint, (c), Zerodur, 1 and (d) hydroxyapatite (50 N). 
Table 2

Hardness and fracture toughness of glasses and ceramics.

\begin{tabular}{|c|c|c|c|c|c|}
\hline & & Crown & Flint & HAP & Zerodur \\
\hline \multirow{2}{*}{$K_{i C}(\mathrm{E}, \mathrm{H})(1)\left(\mathrm{MPa} \mathrm{m}^{\mathbf{1} / 2}\right)$} & Experimental & $0.50 \pm 0.4$ & $0.47 \pm 0.03$ & $1.20 \pm 0.23$ & $0.93 \pm 0.1$ \\
\hline & Literature & $0.58-0.67[46]$ & $0.46-0.54[46]$ & $1.00-1.20[42,43]$ & $0.90-1.10[44,45]$ \\
\hline \multirow[t]{2}{*}{ HV (GPa) } & Experimental & $6.3 \pm 0.3$ & $4.6 \pm 0.3$ & $4.4 \pm 0.6$ & $6.7 \pm 0.6$ \\
\hline & Literature & $6.4-7.3[46]$ & $4.5-4.8[46]$ & $4-5[42,43]$ & $6.2[44,45]$ \\
\hline
\end{tabular}

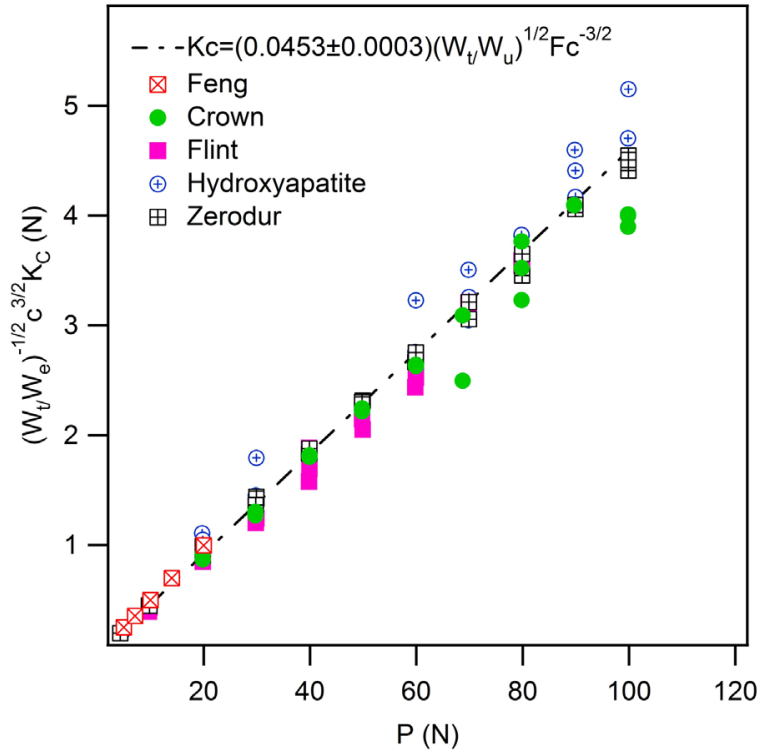

Fig. 9. $\lambda$ parameter for all materials (three tests per load), $\lambda$ parameter is equal to slope of the curve.

between 0.5 and 0.7 [33]. Field et al. [34] associated the pop-in to a change in the cracks propagation mode. For a cube corner tip, these authors linked the crack opening to the length of the pop-in $\left(h_{x}\right)$, the maximal penetration $\left(h_{\max }\right)$ and the equivalent crack length $\left(c_{\text {pop-in }}\right)$ :

$c_{\text {Pop in }}=\sqrt{2} h_{m}+\left(Q \frac{E_{r}}{H M}-\sqrt{2}\right) h_{x}$

where HM is the Martens hardness [35] in GPa and $Q$ a constant estimated to $Q=4.7 \pm 0.2$. (evaluated by Field et al. from tests on fused quartz and glass carbon) or to $Q=3.52 \pm 0.4$. (evaluated by Scholz et al. from tests performed on fused quartz and sapphire) [36].

Since this equation depends on the indenter geometry, it must be recalculated for a Vickers indenter. Using the same approach as Field et al. Fig. 4(b) shows that for a Vickers tip, the equivalent crack length becomes:

$c_{\text {Pop in }}=3.5 h_{m}+\left(Q^{\prime} \frac{E_{r}}{H}-3.5\right) h_{x}$

In the following, as supposed by Field et al. [34], it is assumed that $Q^{\prime}$ is a constant independent of the material. This new constant $Q^{\prime}$ is determined by differentiating the Eq. (9) over the length of the pop-in $\left(h_{x}\right)$ (Eq. (10)):

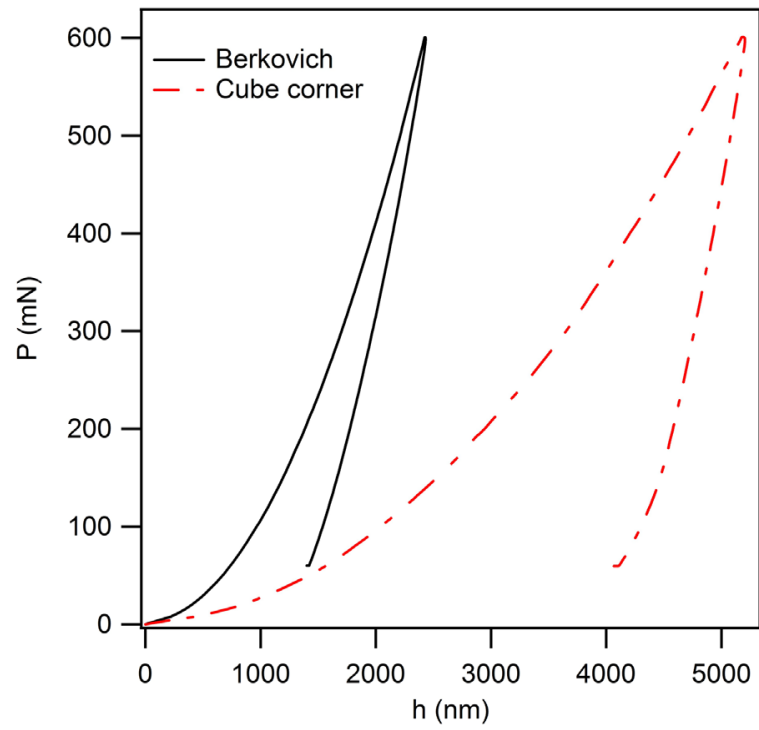

Fig. 10. Load control indentation curves $(600 \mathrm{mN})$ for a Zerodur glass with Berkovich and cube corner indenters.

$\frac{\partial \mathrm{c}}{\partial h_{x}}=Q^{\prime} \frac{E_{r}}{H}-3.5$

The graphical representation of the average crack length (calculated through experimental measurements for the pop-in force) as a function of the displacement of the indenter due to pop-in, allows obtaining this constant.

\subsection{Energy methods}

Fracture toughness measurements for thin films and coatings are commonly obtained from models using crack nucleation energy [21,37-39] (Eq. (11)). Chen [14] shows the validity of this equation, also for bulk materials.

$K_{i c}=\sqrt{\frac{E_{r} U_{\text {rupt }}}{A_{\text {rupt }}}}$

where $U_{\text {rupt }}$ is the energy needed to produce a crack and $A_{\text {rupt }}$ the crack area. For a half Penny crack, the crack area is $\pi c^{2}$. Thus, Eq. (11) becomes:

$K_{i c}=\sqrt{\frac{E_{r} U_{r u p t}}{\pi c^{2}}}$

Table 3

Materials average fracture toughness using the $W_{t} / W_{e}$ ratio (Eq.(4)).

\begin{tabular}{|c|c|c|c|c|c|}
\hline Fracture toughness & Equation & Crown & Flint & HAP & Zerodur \\
\hline$K_{i c}\left(W_{t}, W_{u}\right)(4)$ & $K_{c}=\lambda\left(\frac{W_{t}}{W_{e}}\right)^{1 / 2} \frac{P}{c^{3 / 2}}$ & $0.52 \pm 0.03$ & $0.5 \pm 0.02$ & $1.30 \pm 0.23$ & $0.93 \pm 0.09$ \\
\hline
\end{tabular}


a)

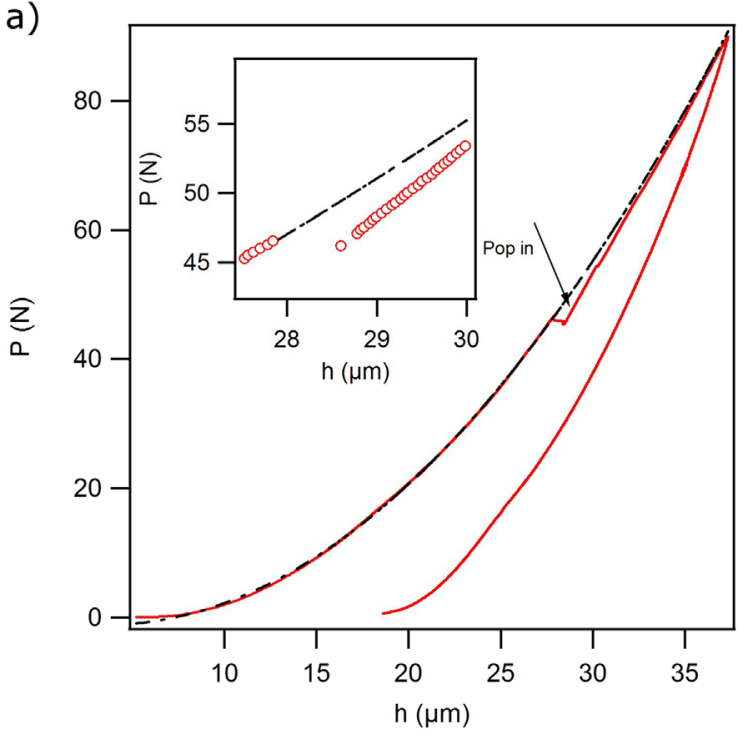

b)

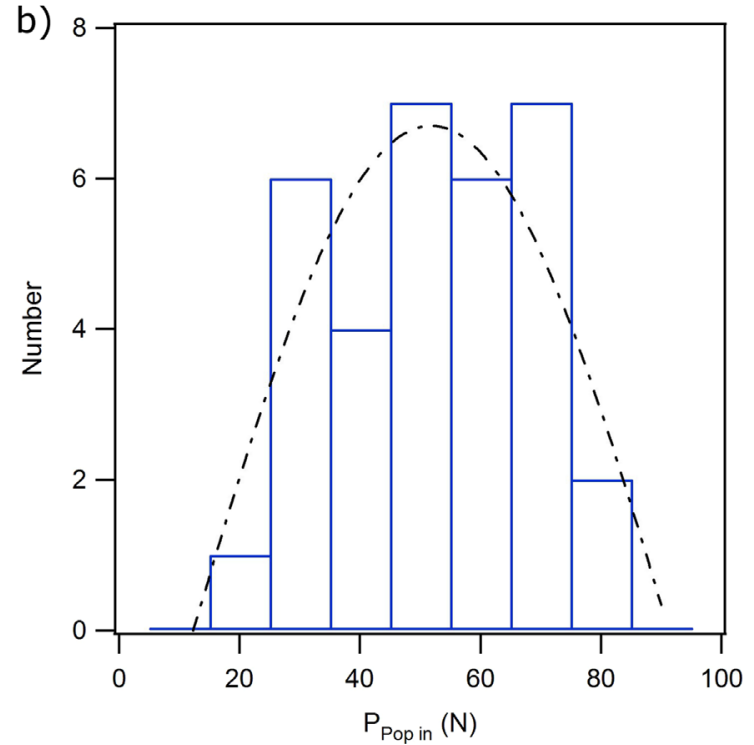

Fig. 11. Representation of: (a) a typical indentation curve of Zerodur glass and (b) distribution of critical cracking forces.

a)

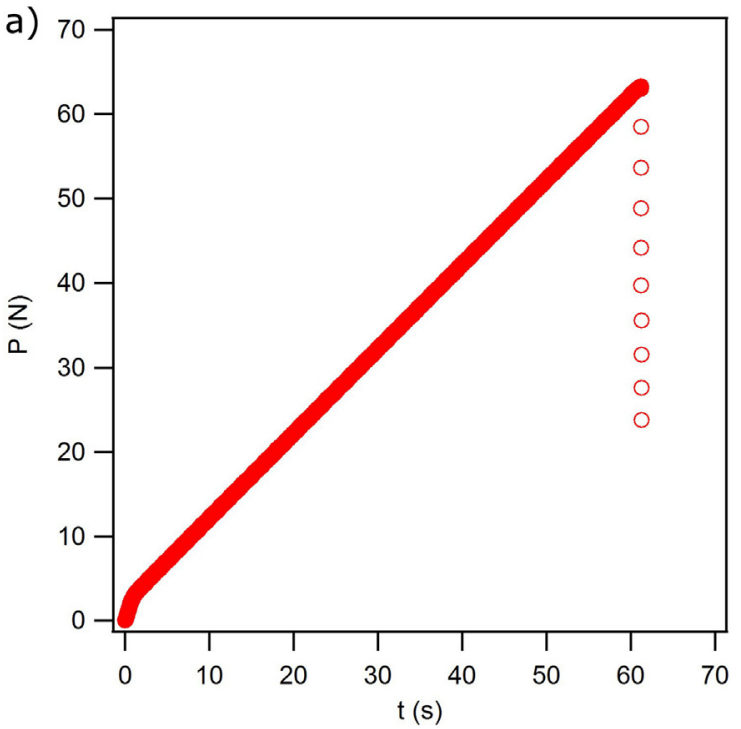

b)

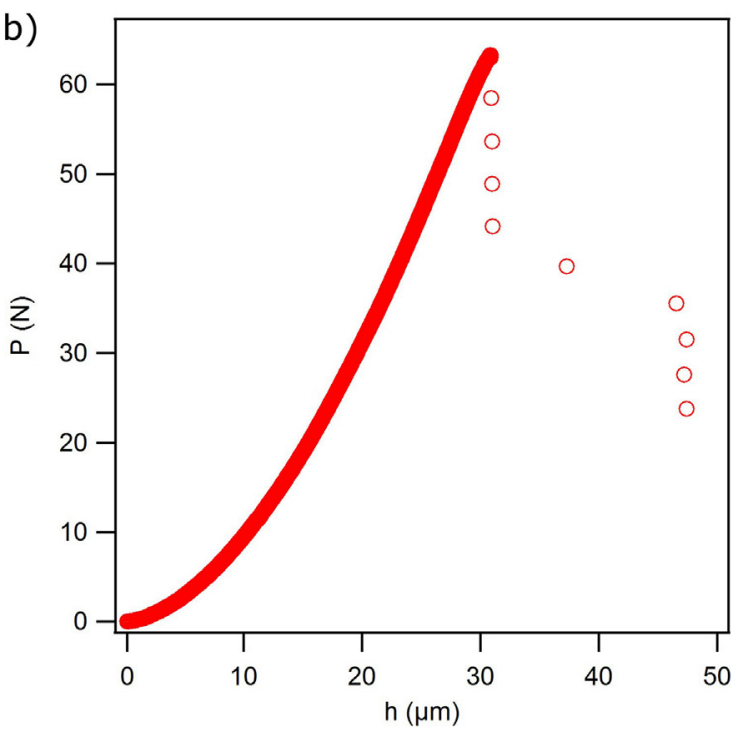

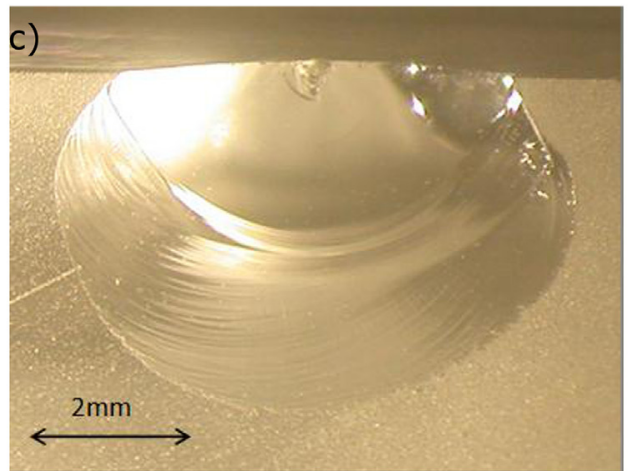

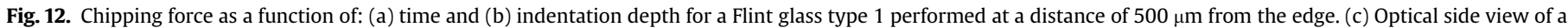
flake in Crown glass for an edge distance of $1 \mathrm{~mm}$.

\section{Material and methods}

In order to compare different methods for toughness determination by indentation, four glasses and ceramics have been tested. Materials studied here are:
1. A Crown glass type BK7 (crown glass)

2. A Flint glass type SF17 (heavy flint glass)

3. A Zerodur glass

4. A hydroxyapatite ceramic (HAP)

Crown, Flint and Zerodur glasses are silica based. Crown is 

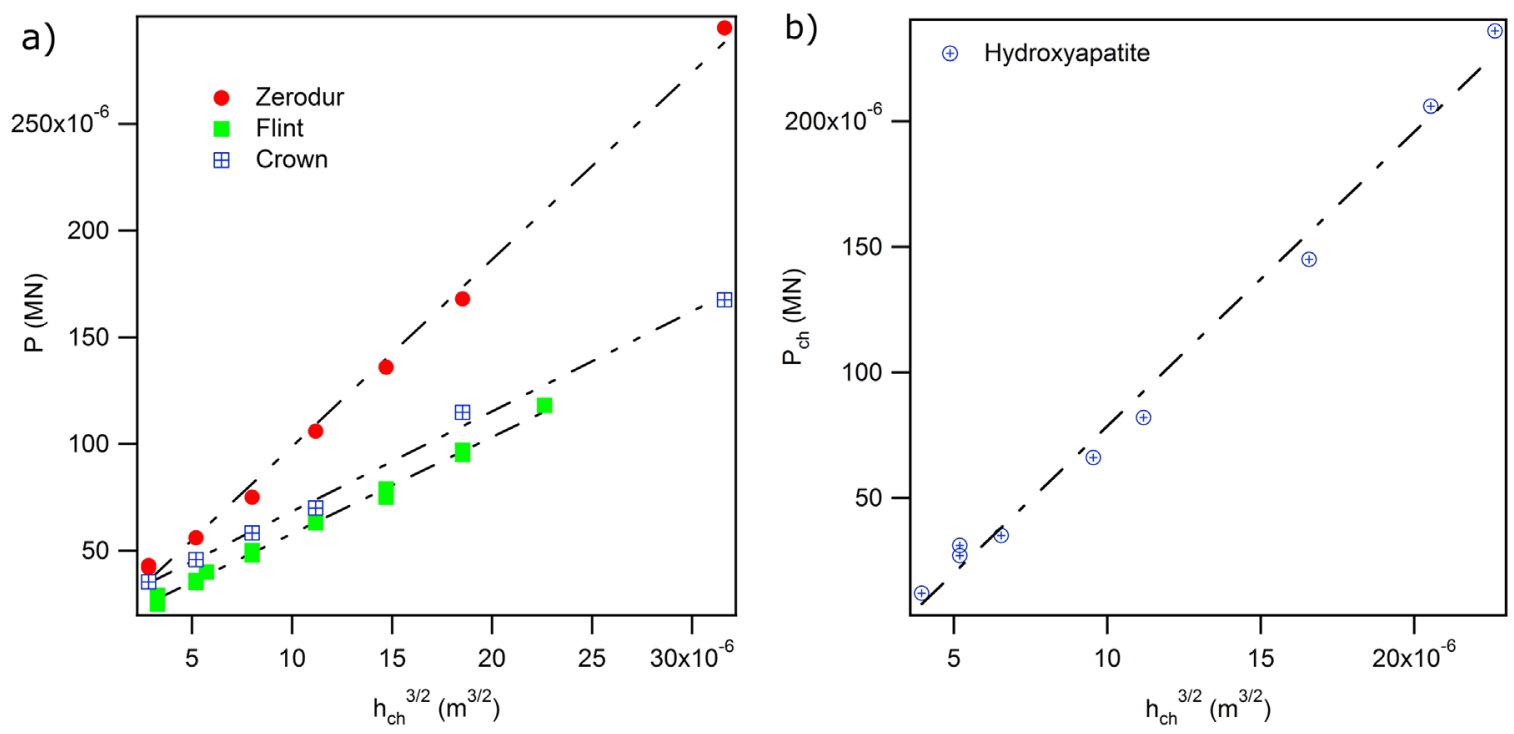

Fig. 13. Evolution of the chipping critical loads as a function of the distance to the edge, in the case of (a) Zerodur and glasses and (b) hydroxyapatite.

Table 4

Materials average fracture toughness calculated by the edge chipping method.

\begin{tabular}{|c|c|c|c|c|c|}
\hline Fracture toughness & Equation & Crown & Flint & HAP & Zerodur \\
\hline$K_{i c}\left(\mathbf{P}_{\mathrm{Ch}}, \mathrm{H}_{\mathrm{Ch}}\right)(6)$ & $K_{C}=\frac{1}{\beta} \frac{P_{C h}}{h_{C h}{ }^{3 / 2}}$ & $0.5 \pm 0.03$ & $0.49 \pm 0.02$ & $1.26 \pm 0.43$ & $0.94 \pm 0.06$ \\
\hline
\end{tabular}

widely used in optical applications and is composed of silica, sodium hydroxide (soda) and calcium. Flint glass, rich in lead, is generally used for glassware, optical devices and screen protection. Vitroceramic glasses such as Zerodur are made of microcrystals spread in a glassy matrix. Hydroxyapatite, widely used for biomedical applications, was sintered by microwave [40]. Its grain size, determined on SEM micrographs, is about $1 \mu \mathrm{m}$ and its relative density, measured by Archimedes method, is equal to $99.6 \%$.

Surface preparation was carried out by using increasing grade $\mathrm{SiC}$ grinding papers and a final $1 \mu \mathrm{m}$ diamond slurry.

Elastic moduli were estimated with a nanoindenter MTS XP (USA) equipped with a Berkovich and a cube corner tips. Tests have been performed at a constant loading rate of $40 \mathrm{mN} / \mathrm{s}$. Indentation curves were analyzed with by the Oliver and Parr method [41].

Micro and macro indentation tests were performed with an instrumented machine Zwick/Roell ZHU 2.5 (Germany). This instrument, equipped with a Vickers tip, allows a load range from 5 to $2500 \mathrm{~N}$. Tests were performed in load control mode, at a constant rate of $1 \mathrm{~N} / \mathrm{s}$, with a dwell time of $10 \mathrm{~s}$ at maximum load. Three tests were performed for each load, starting at $10 \mathrm{~N}$ and finishing at $100 \mathrm{~N}$ with incremental steps of $10 \mathrm{~N}$. Diagonals imprints and average crack lengths were measured by using the integrated optical microscope. Hardness and fracture toughness are thus easily calculable. Time between the removal of the indenter and the measure of imprints is below one minute, limiting issues from cracks instability.

Indentation tests for the edge chipping method were performed with a Vickers tip at a distance from sample's edge ranging from 100 to $1000 \mu \mathrm{m}$ by $100 \mu \mathrm{m}$ steps (Zwick/Roell ZHU 2.5 indenter). The displacement reference relies on the surface sample ensures a good stability of the sample. The edge distance was measured through the integrated optical microscope of the indenter. Moreover the motorized X-Y table allows accurate positioning of the sample. The loading rate is set to $1 \mathrm{~N} / \mathrm{s}$. Three tests were performed for each edge distance. The chipping load, defined as the critical one when a chip is formed, is simply determined from the load-displacement curve.

\section{Results}

Several methods for fracture toughness measurement require the elastic modulus of the tested materials. Fig. 5 shows a typical load-displacement curve performed on Zerodur glass with the nanoindenter equipped with a Berkovich tip. Nanoindentation curves are analyzed with the Oliver and Pharr [41] method and reported in Table 1 . These results are in good agreement those reported in with previous studies [42-47].

\subsection{Methods using crack length measurement}

Typical load-displacement $(P-h)$ curves, for a maximum applied load of $50 \mathrm{~N}$ are represented Fig. 6. Different mechanical behaviors, as will be seen later, can be identified. Fig. 7 shows typical imprints obtained on the four materials at $50 \mathrm{~N}$. Wide Half-Penny cracks ( $c$ ) $a>2.5$ ) have been identified by successive polishing, allowing the use of the previous equations.

\subsubsection{Classical method (Eq. (1))}

Tests are performed with the instrumented indenter applying loads ranging from 5 to 100 N. For the four materials, Fig. 8 shows a linear trend between the average crack length at power $3 / 2$ and the indentation load. Whatever the applied load, fracture toughness is constant, which confirms that the polishing process did not generate residual stress at the sample surface.

Vickers hardness was calculated from diagonal length and verified with the residual imprint depth. Fracture toughness was obtained with Eq. (1) (Table 2). This method takes into account average crack length, Vickers hardness, Young's modulus and applied load. Results are in good agreement with those obtained by other authors [42-46] (Table 2). 

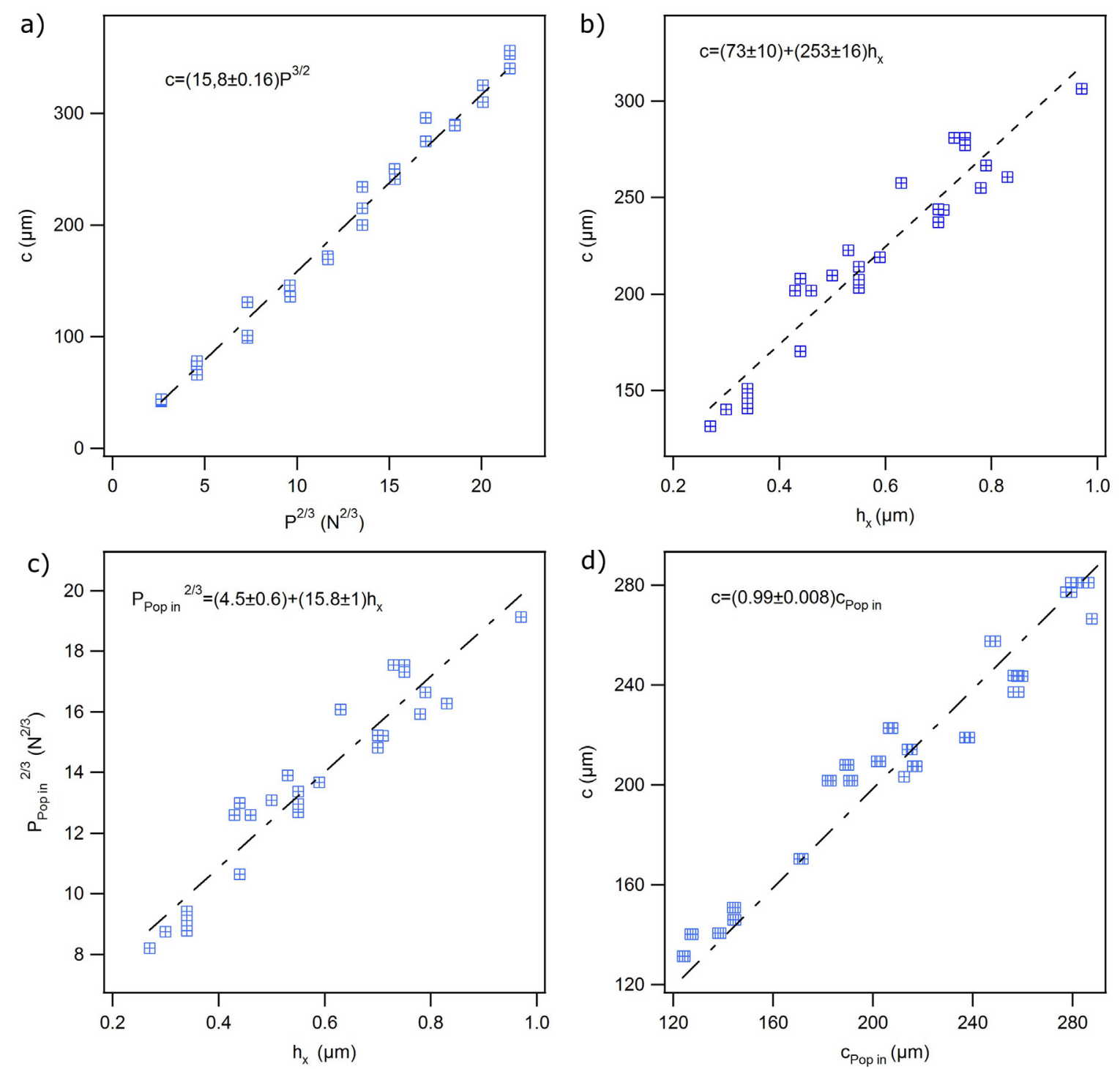

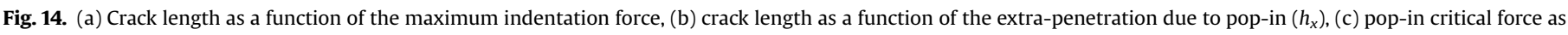
a function of the extra-penetration and (d) experimental crack lengths as a function of theoretical crack length (Eq. (8)).

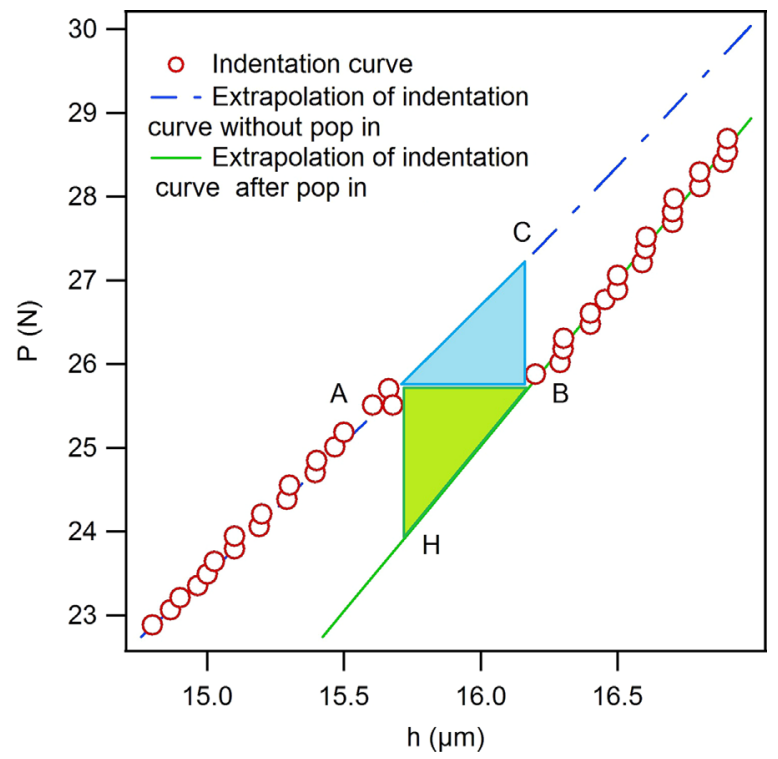

Fig. 15. Load control indentation curve showing different areas used for calculating the cracking energy.

\subsubsection{Method using the ratio $W_{t} / W_{e}$ (Eq. (4))}

From the previous method, results dispersion can be reduced by replacing the $E / H$ ratio by the ratio of total over elastic deformation energies. Fig. 9 shows $\left(W_{t} / W_{e}\right)^{1 / 2} c^{3 / 2} K_{i c}$ as a function of the applied load. Results obtained by Feng et al. [25] on silica, soda lime glass and aluminosilicate are also added on Fig. 9. The curve exhibits a linear behavior which allows a determination of $\lambda$. This constant, $\lambda=0.0453$, is close to the value obtained by Feng et al. (0.0498) for loads between 5 and $20 \mathrm{~N}$. This slight difference can be attributed to the high loads (up to $100 \mathrm{~N}$ ) used in the present study.

A constant $\lambda$ equal to 0.0453 corresponds to $k^{-1}=7.6$ (Eq. (4)). This result is close to the result of Choi et al. [48] who find $k^{-1}=7.3$ for a ratio $W_{e} / W_{t}$ lower than 0.15 . These results are lower than those obtained by Feng et al. $\left(k^{-1} \sim 9\right)$ but higher than the value of 5 generally reported in literature $[21,23,49]$. This can be explained by several factors such as very high load (lower hardness) or the use of Vickers hardness (calculated with contact area) instead of instrumented hardness (calculated with projected contact area).

Fracture toughness values calculated with Eq. (4) and with $\lambda=0.0453$ are listed in Table 3 . 
Table 5

Average fracture toughness calculated with different equations (values are associated with their standard deviation).

\begin{tabular}{|c|c|c|c|c|c|}
\hline Fracture toughness & Equation & Crown & Flint & HAP & Zerodur \\
\hline$K_{i c}(\mathbf{E}, \mathrm{H})(\mathbf{1})$ & $K_{c}=\chi\left(\frac{E}{H_{V}}\right)^{1 / 2} \frac{P}{c^{3 / 2}}$ & $0.50 \pm 0.04$ & $0.47 \pm 0.03$ & $1.20 \pm 0.23$ & $0.93 \pm 0.100$ \\
\hline$K_{i c}\left(W_{t}, W_{u}\right)(4)$ & $K_{c}=\lambda\left(\frac{W_{t}}{W_{e}}\right)^{1 / 2} \frac{P}{c^{3 / 2}}$ & $0.52 \pm 0.03$ & $0.5 \pm 0.02$ & $1.30 \pm 0.23$ & $0.93 \pm 0.09$ \\
\hline$K_{i c}\left(P_{C h}, H_{C h}\right)(6)$ & $K_{C}=\frac{1}{\gamma} \frac{P_{C h}}{h_{C h^{3 / 2}}}$ & $0.5 \pm 0.03$ & $0.49 \pm 0.02$ & $1.26 \pm 0.43$ & $0.94 \pm 0.06$ \\
\hline$K_{i c}(P o p-i n)(1)(9)$ & $\mathrm{c}=h_{m} \cot \varphi+\left(Q \frac{E_{r}}{H}-1\right) h_{x} \cot \varphi$ & & & & $0.91 \pm 0.07$ \\
\hline$K_{i c}\left(\mathbf{P}_{\text {crit }}\right)(5)$ & $K_{C}=\left(\frac{1}{\beta} \frac{P_{C}}{H^{3}}\right)^{1 / 4}$ & & & & $0.90 \pm 0.09$ \\
\hline$K_{i c}\left(U_{A B C}\right)(12)$ & $K_{C}=\sqrt{\frac{E_{r} U_{A B C}}{A_{\text {rupt }}}}$ & & & & $0.76 \pm 0.17$ \\
\hline$K_{i c}\left(U_{A B H}\right)(12)$ & $K_{c}=\sqrt{\frac{E r U_{A B H}}{A_{\text {rupt }}}}$ & & & & $0.8 \pm 0.20$ \\
\hline
\end{tabular}

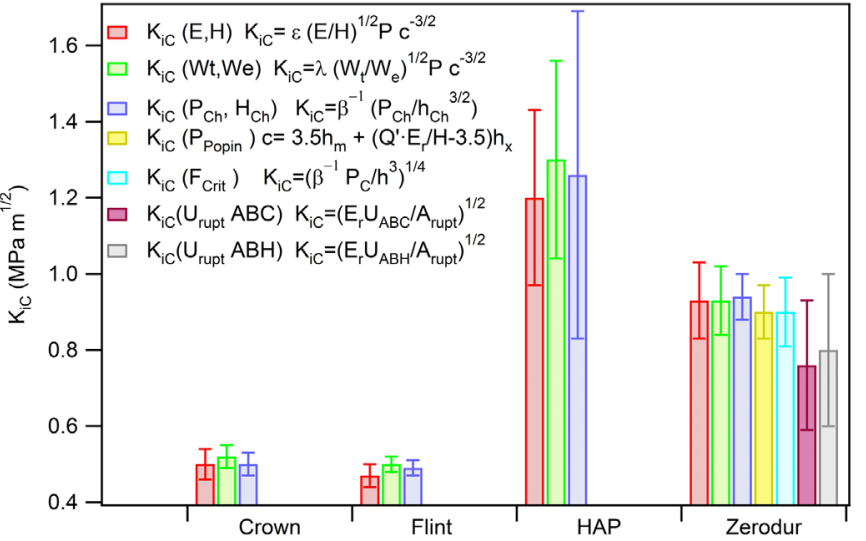

Fig. 16. Materials fracture toughness calculated via different methods.

\subsection{Method that do not require crack length measurement}

Methods that do not require crack length measurement need the determination of the critical force for crack nucleation or popin.

In order to observe pop-in, a cube corner tip has been used with a maximum load of $600 \mathrm{mN}$ (Fig. 10). Due to the sharpness of the cube corner, for the same applied load, the penetration of the cube corner is larger than in the case of a Berkovich tip.

A closer look to the indentation curves does not reveal any popin. To emphasis a possible pop-in on the loading curve, the force has been differentiated relative to the displacement. However no pop-in is observed. Only tests performed on Zerodur with the macroindenter show pop-ins. Thus, these methods will be only used for this material.

\subsubsection{Critical load method (Eq. (6))}

Load-displacement curve in Zerodur shows sudden bursts (Fig. 11(a)) which are commonly called pop-in. In the case of Zerodur the pop-in always occurs with an acoustic emission that can be heard by human hear. This emission corresponds to the critical force $P_{c}$ from which the propagation mode of the crack changes [34].

This critical force follow a Gaussian-like distribution (Fig. 11(b)) centered around $51 \mathrm{~N}$ with a standard deviation of $\pm 18 \mathrm{~N}$. The toughness can be calculated using this force in Eq. (5). The average toughness of Zerodur, calculated over 33 tests, is equal to $0.90 \pm 0.09 \mathrm{MPa} \mathrm{m}^{1 / 2}$. This result is very close to those obtained with previous methods.

\subsubsection{Edge chipping method (Eq. (6))}

Edge chipping tests are performed at an edge distance ranging from 100 to $1000 \mu \mathrm{m}$. The fracture force is accurately determined on the load-displacement curve (Fig. 12). Fracture appears for a force between 5 and $300 \mathrm{~N}$. A chip observed on a Crown glass is shown on Fig. 12(c).

Fig. 13 represents the critical chipping force versus edge distance. Glasses, belonging to the same family, are reported in Fig. 13 (a). Hydroxyapatite shows a different behavior with an intercept significantly different from the one of glasses. As previously reported in literature $[30,32]$, the critical force is proportional to
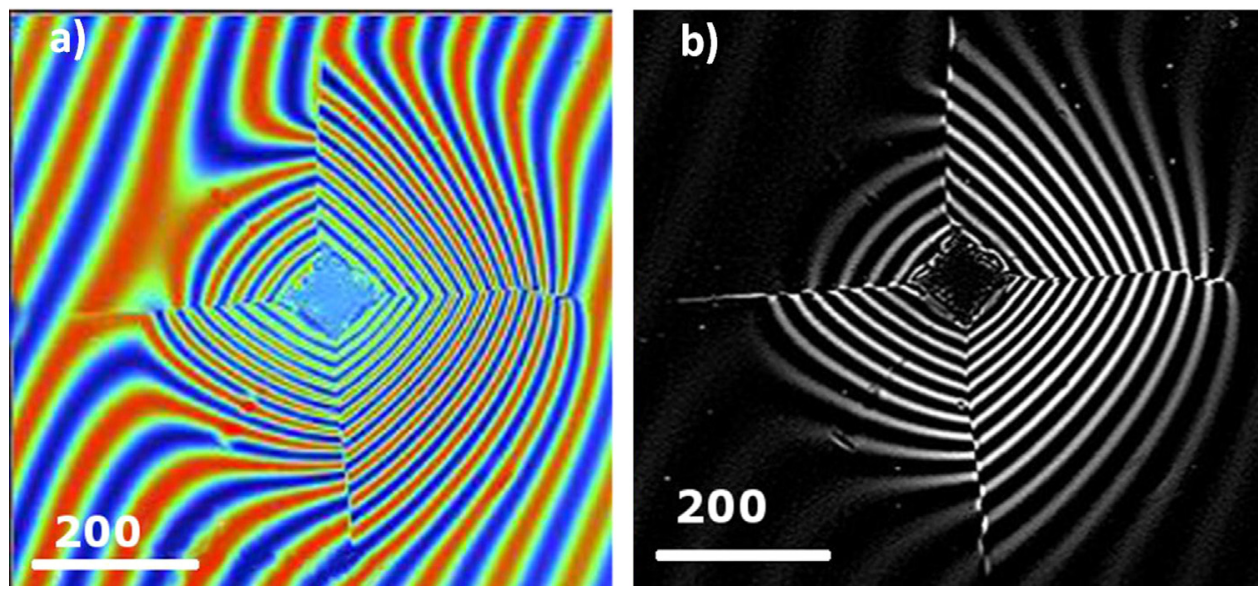

Fig. 17. Interference pattern showing cracks surrounding an imprint: (a) color raw image; (b) derived image. 
$\mathrm{h}_{\mathrm{ch}}{ }^{2 / 3}$. The average fracture toughness of each material, determined with Eq. (6) and a $\gamma$ constant equal to $9.3 \pm 1.3$ [32], is reported in Table 4 . The results are comparable to those obtained with previous methods.

\subsubsection{Pop-in method}

Field et al. recommend the use of Eq. (8) to determine crack length. However, this equation requests a $Q^{\prime}$ constant, supposedly independent on the material [34], which is unknown when using a Vickers tip. Indeed, pop-in appears at high loads on zerodur sample. It is thus possible to determine this $Q^{\prime}$ constant by comparing results with those obtained with classical method involving crack length measurement.

Fig. 14(a) shows evolution of crack length as a function of maximal applied load. A linear regression of experimental data points gives the equation: $c=15.8 P^{2 / 3}$ with $c$ in $\mu \mathrm{m}$ and $P$ in $\mathrm{N}$. Thus, it is possible to plot $c$ as a function of $h_{x}$ for each critical load $P_{\text {pop-in }}$ (Fig. 14(b)). The constant $Q^{\prime}$ is determined from Fig. 14(b,c) which show the relation between $c$ and $h_{x}$ and between $P_{p o p-i n}$ and $h_{x}$. Finally, $Q^{\prime}=18.6$ for a Vickers tip and hardness (Eq. (10)).

Fig. 14(d) shows the relation between the experimentally measured crack length and $c_{\text {pop-in }}$ calculated with Eq. (8). A good agreement is evidenced between these two parameters. The $P_{\text {pop-in }}$ force and the $c_{\text {pop-in }}$ crack length are reported in Eq. (1), which enables to obtain the material fracture toughness without average crack length measurement. The average fracture toughness is found to be equal to $0.91 \pm 0.07 \mathrm{MPa} \mathrm{m}^{1 / 2}$, which is similar to the results obtained with by using previous methods.

\subsection{Energy method}

Eq. (12) gives the toughness as a function of the reduced Young's modulus, fracture energy and rupture area $\pi c^{2}$ in the case of a Half-Penny crack. The average crack length $c$ is obtained from the regression $c=15.8 P^{2 / 3}$ detailed in the previous paragraph. According to different authors, this fracture energy $U_{\text {rupt }}$ can be calculated from the area of the $\mathrm{ABC}$ [50] or $\mathrm{ABH}$ [51] triangles (Fig. 15(b)). These two triangles are built with extrapolation of indentation curves before and after pop-in.

The average fracture toughness obtained is respectively of $0.76 \pm 0.17 \mathrm{MPa} \mathrm{m}^{1 / 2}$ and $0.80 \pm 0.20 \mathrm{MPa} \mathrm{m}^{1 / 2}$ when considering the $\mathrm{ABC}$ and the $\mathrm{ABH}$ triangle areas. These results are a little bit lower than those obtained with other methods, but still matches with Chen's work [14] who reported a lowering of toughness by $20 \%$ when using energy method.

\section{Discussion}

Table 5 summarizes fracture toughness results obtained by indentation techniques using the different methods. Each result is associated to its standard deviation regardless of uncertainties due to empirical constants of models $(\chi, \lambda, \beta, \gamma \ldots)$. Equations reported in this paper give a critical toughness with little dispersion (Fig. 16). In spite of empirical constants uncertainties $(\chi=0.016 \pm 0.004, \gamma=9.3 \pm 1.3 \ldots)$ which can induce a noticeable scattering, the average fracture toughness is very similar whatever the method employed. Only energy method, which does not use constant, shows lower values.

Eq. (1), which is the most employed to calculate $K_{i c}(E, H)$, can be used as a benchmark to compare with others studies. Moreover, this method does not require instrumented test. Except uncertainty due to the use of the $\chi$ coefficient, main errors come from the crack length measurement and from the Young's modulus determination.

In order to improve the accuracy of the crack length measurement, Miyazaki et al. [26,52] propose to coat the sample with a thin layer of $100 \mathrm{~nm}$ thick paint. This has for consequence to emphasis optical contrast in particular at the end of the crack. These authors also suggested using higher magnification. In this paper, an original approach using confocal interferometry is proposed. The crack propagation leads to topographical discontinuity on both sides of the crack. If topography is accurately characterized, the determination of the crack end is significantly improved. Fig. 17 shows an indent with surrounded cracks observed with the Wyko NT 9300 interferometry confocal microscope.

Fig. 17 shows sudden changes in the fringes direction corresponding to a slope break from both parts of the crack. The derivative image (Fig. 17(b)) makes easier the identification of the local slope break by local contrast analysis. A reduction of $50 \%$ in the average crack length determination has been evidenced $\left(K_{i C}\right.$ crown $=0.50 \pm 0.2$ )

To reduce uncertainty due to the Young's modulus determination it is proposed to replace the $E / H$ ratio by $W_{t} / W_{u}$. The $\lambda$ constant of Eq. (3) has been determined as $\lambda=0.0453$, in good agreement with previous works conducted at lower loads [25]. Thereby $K_{i c}\left(W_{t}, W_{u}\right)$ was calculated with lower standard deviation compared to results from Eq. (1). The use of Eq. (3) needs to record the load-displacement curve, in order to calculate deformation energies.

Method based on critical force $K_{i c}\left(P_{c}\right)$ (Eq. (4)) is fast and effective. This method does not need the crack length measurement, but it is mandatory to know the critical force from which the crack suddenly propagates. Thus, only Zerodur fracture toughness was calculated.

Edge chipping tests do not need the crack length measurement (Eq. (6)). Results are accurate and self-consistent. The limitation is that the sample needs to be polished on two perfectly perpendicular faces. Several tests have been performed at different edge distance in order to plot a straight line with a well-defined slope. It is of interest to optimize the number of data points by selecting optimal edge distances.

The use of the method using the pop-in phenomenon was extended by determining the $Q^{\prime}$ coefficient for a Vickers indenter. Results are close to those obtained with others methods and dispersion is very small. There is no need any more to measure the crack length, but the recording of load-displacement curve is required. Measures of $h_{x}$ still remain delicate and should be done with accuracy. Moreover, this method needs a pop-in during indentation. Thus, only Zerodur fracture toughness was calculated.

Equation based on cracking energy is the only method which does not need an empirical constant. Thus uncertainties are only limited to experimental factors and final results are free of uncertainty due to the model. Cracking energy can be calculated from two different areas depending on authors. A disparity of $20 \%$ is observed for this method whatever the area definition. This method is commonly employed for coated materials, only Chen [14] uses it for bulk materials. He reported similar disparity for silicon carbide and silica when using the ABC area. This method requires the knowledge of crack length, load-displacement curve, curve extrapolation and finally integral calculus.

\section{Conclusions}

This work reports an original comparison of seven different methods for fracture toughness determination by indentation techniques.

For this purpose, it was necessary to experimentally determine some constant necessary for the fracture toughness determination, and unknown for Vickers indentation or for the load range considered. Thus, the $Q^{\prime}$ parameter, used to calculate the equivalent 
length of crack when pop-in occurs, was experimentally found to be equal to 18.6 for a Vickers tip and Vickers hardness. This parameter was determined with experimental data obtained on Zerodur glass. Although Field et al. suppose that this constant is unique, it should be confirmed on other materials. Works are in progress but until now, no other material exhibiting a pop-in in Vickers macro indentation has been analyzed. Moreover, the $\lambda$ constant needed to calculate fracture toughness with the ratio $W_{t}$ $/ W_{u}$ was determined for loads between 5 and $100 \mathrm{~N}$. For a Vickers tip, $\lambda$ is equal to 0.0453 .

Thus, the methods reported here give consistent results for all the brittle materials tested, except the energy method, which lead to lower (about 20\%) fracture toughness results. Thus, all these methods, except energy method, should be equally used for the fracture toughness determination of brittle materials, depending on the experimental inputs known.

Finally, methods that do not require the measurement of crack length are fast and suitable for glasses and ceramics. However most of these methods need the appearance of a pop-in during the loading and only few materials are prone to exhibit this phenomenon.

\section{References}

[1] M. Barlet, J.-M. Delaye, T. Charpentier, M. Gennisson, D. Bonamy, T. Rouxel, C. L. Rountree, Hardness and toughness of sodium borosilicate glasses via Vickers's indentations, J. Non-Cryst. Solids 417-418 (2015) 66-79.

[2] T. Wilantewicz, Crack Initiation Behavior of Optical Glasses from Vickers Indentation, Alfred University, New York, 2005.

[3] M. Buijs, K.K. Houten, A model for lapping of glass, J. Mater. Sci. 28 (11) (1993) 3014-3020.

[4] J. Larmor, VI. The influence of flaws and air-cavities on the strength of materials, Philos. Mag. Ser. 533 (200) (1892) 70-78.

[5] A.A. Griffith, The phenomena of rupture and flow in solids, Philos. Trans. R. Soc. Lond. Ser. Contain. Pap. Math. Phys. Character 221 (1921) 163-198.

[6] G.R. Irwin, Plastic zone near a crack and fracture toughness, in: Proceedings of the Seventh Sagamore Conference, Syracure University Research Institute, vol. IV, 1960, pp. 63-76.

[7] J.E. Srawley, Wide range stress intensity factor expressions for ASTM E 399 standard fracture toughness specimens, Int. J. Fract. 12 (3) (1976) 475-476.

[8] H. Wang, P. Pallav, G. Isgrò, A.J. Feilzer, Fracture toughness comparison of three test methods with four dental porcelains, Dent. Mater. 23 (7) (2007) 905-910.

[9] S.S. Scherrer, I.L. Denry, H.W.A. Wiskott, Comparison of three fracture toughness testing techniques using a dental glass and a dental ceramic, Dent. Mater. 14 (4) (1998) 246-255.

[10] A. Iost, Détermination de la ténacité de matériaux fragiles ou ductiles à partir de l'essai d'indentation, Metall. Res. Technol. 110 (3) (2013) 215-233.

[11] S. Palmqvist, Method of determining the toughness of brittle materials, particularly sintered carbides, Jernkontorets Ann. 141 (1957) 300-307.

[12] B.R. Lawn, D.B. Marshall, Indentation fracture and strength degradation in ceramics, in: R.C. Bradt, D.P.H. Hasselman, F.F. Lange (Eds.), Flaws and Testing, Springer, US, 1978, pp. 205-229.

[13] R.C. Lueth, Determination of fracture toughness parameters for tungsten carbide-cobalt alloys, in: R.C. Bradt, D.P.H. Hasselman, F.F. Lange (Eds.), Fracture Mechanics of Ceramics, Springer, US, 1974, pp. 791-806.

[14] J. Chen, Energy Based Models to Determine Fracture Toughness of Thin Coated Systems by Nanoindentation (Newcastle University eTheses), Newcastle University, Newcastle, 2006.

[15] G.R. Anstis, P. Chantikul, B.R. Lawn, D.B. Marshall, A critical evaluation of indentation techniques for measuring fracture toughness. I.- Direct crack measurements, J. Am. Ceram. Soc. 64 (9) (1981) 533-538.

[16] P. Chantikul, G.R. Anstis, B.R. Lawn, D.B. Marshall, A critical evaluation of indentation techniques for measuring fracture toughness. II.- Strength method, J. Am. Ceram. Soc. 64 (9) (1981) 539-543.

[17] N. Cuadrado, D. Casellas, M. Anglada, E. Jiménez-Piqué, Evaluation of fracture toughness of small volumes by means of cube-corner nanoindentation, Scr. Mater. 66 (9) (2012) 670-673.

[18] D.S. Harding, W.C. Oliver, G.M. Pharr, Cracking during nanoindentation and its use in the measurement of fracture toughness, in: Proceedings of Symposium B2 - Thin Films: Stresses and Mechanical Properties V, vol. 356, 1994.

[19] M.T. Laugier, New formula for indentation toughness in ceramics, J. Mater. Sci. Lett. 6 (3) (1987) 355-356.

[20] J. Gong, Determining indentation toughness by incorporating true hardness into fracture mechanics equations, J. Eur. Ceram. Soc. 19 (8) (1999) 1585-1592.

[21] J. Malzbender, Comment on the determination of mechanical properties from the energy dissipated during indentation, J. Mater. Res. 20 (5) (2005)
1090-1092.

[22] J. Chen, S.J. Bull, Relation between the ratio of elastic work to the total work of indentation and the ratio of hardness to Young's modulus for a perfect conical tip, J. Mater. Res. 24 (3) (2009) 590-598.

[23] Y.-T. Cheng, Z. Li, C.-M. Cheng, Scaling relationships for indentation measurements, Philos. Mag. A 82 (10) (2002) 1821-1829.

[24] T. Zhang, Y. Feng, R. Yang, P. Jiang, A method to determine fracture toughness using cube-corner indentation, Scr. Mater. 62 (4) (2010) 199-201.

[25] Y. Feng, T. Zhang, R. Yang, A work approach to determine Vickers indentation fracture toughness, J. Am. Ceram. Soc. 94 (2) (2011) 332-335.

[26] H. Miyazaki, Y. Yoshizawa, Novel measurement technique of crack length for indentation fracture (IF) method using high contrast image of crack tips through thin film coating, J. Eur. Ceram. Soc. 35 (10) (2015) 2943-2948.

[27] F.C. Frank, B.R. Lawn, On the theory of hertzian fracture, Proc. R. Soc. Lond. Math. Phys. Eng. Sci. 299 (1458) (1967) 291-306.

[28] B.R. Lawn, A.G. Evans, A model for crack initiation in elastic/plastic indentation fields, J. Mater. Sci. 12 (11) (1977) 2195-2199.

[29] G.A. Gogotsi, S.P. Mudrik, Glasses: new approach to fracture behavior analysis, J. Non-Cryst. Solids 356 (20-22) (2010) 1021-1026.

[30] G.A. Gogotsi, Fracture toughness testing of materials by the EF method, Inorg. Mater. 42 (5) (2006) 567-572.

[31] R. Morrell, A.J. Gant, Edge chipping of hard materials, Int. J. Refract. Met. Hard Mater. 19 (4-6) (2001) 293-301.

[32] H. Chai, B.R. Lawn, A universal relation for edge chipping from sharp contacts in brittle materials: a simple means of toughness evaluation, Acta Mater. 55 (7) (2007) 2555-2561.

[33] H. Tada, P.C. Paris, G.R. Irwin, The Stress Analysis of Cracks Handbook, ASME Press, New York, 2000.

[34] J.S. Field, M.V. Swain, R.D. Dukino, Determination of fracture toughness from the extra penetration produced by indentation-induced pop-in, J. Mater. Res. 18 (6) (2003) 1412-1419.

[35] J. Gubicza, A. Juhász, J. Lendvai, A new method for hardness determination from depth sensing indentation tests, J. Mater. Res. 11 (12) (1996) 2964-2967.

[36] T. Scholz, G.A. Schneider, J. Muñoz-Saldaña, M.V. Swain, Fracture toughness from submicron derived indentation cracks, Appl. Phys. Lett. 84 (16) (2004) 3055-3057.

[37] J.D. Toonder, J. Malzbender, G.D. With, R. Balkenende, Fracture toughness and adhesion energy of sol-gel coatings on glass, J. Mater. Res. 17 (1) (2002) 224-233.

[38] J. Malzbender, J.M.J. den Toonder, A.R. Balkenende, G. de With, Measuring mechanical properties of coatings: a methodology applied to nano-particlefilled sol-gel coatings on glass, Mater. Sci. Eng. R. Rep. 36 (2-3) (2002) 47-103.

[39] J. Malzbender, G. de With, Energy dissipation, fracture toughness and the indentation load-displacement curve of coated materials, Surf. Coat. Technol. 135 (1) (2000) 60-68.

[40] A. Thuault, E. Savary, J.-C. Hornez, G. Moreau, M. Descamps, S. Marinel, A. Leriche, Improvement of the hydroxyapatite mechanical properties by direct microwave sintering in single mode cavity, J. Eur. Ceram. Soc. 34 (7) (2014) 1865-1871.

[41] W.C. Oliver, G.M. Pharr, An improved technique for determining hardness and elastic modulus using load and displacement sensing indentation experiments, J. Mater. Res. 7 (6) (1992) 1564-1583.

[42] K. Ioku, M. Yoshimura, S. Sōmiya, Microstructure and mechanical properties of hydroxyapatite ceramics with zirconia dispersion prepared by post-sintering, Biomaterials 11 (1) (1990) 57-61.

[43] W. Suchanek, M. Yashima, M. Kakihana, M. Yoshimura, Processing and mechanical properties of hydroxyapatite reinforced with hydroxyapatite whiskers, Biomaterials 17 (17) (1996) 1715-1723.

[44] M.J. Viens, Fracture toughness and crack growth of Zerodur, Maryland, NASA Technical Memorandum 4185, 1990.

[45] X. Tonnellier, P. Morantz, P. Shore, A. Baldwin, R. Evans, D.D. Walker, Subsurface damage in precision ground $\mathrm{ULE}^{\mathbb{R}}$ and Zerodur ${ }^{\mathbb{R}}$ surfaces, Opt. Express 15 (19) (2007) 12197.

[46] R.D. Dukino, M.V. Swain, Comparative measurement of indentation fracture toughness with berkovich and Vickers indenters, J. Am. Ceram. Soc. 75 (12) (1992) 3299-3304.

[47] Kurt Nattermann, N. Neuroth, Robert J. Scheller, Mechanical properties, 3rd ed., The Properties of Optical Glass (Schott Series on Glass and Glass Ceramics), Hardcover: Springer, 2004, pp. 179-198.

[48] Y. Choi, H.-S. Lee, D. Kwon, Analysis of sharp-tip-indentation load-depth curve for contact area determination taking into account pile-up and sink-in effects, J. Mater. Res. 19 (11) (2004) 3307-3315.

[49] D. Ma, O.C. Wo, J. Liu, J. He, Determination of Young's modulus by nanoindentation, Sci. China Ser. E Technol. Sci. 47 (4) (2004) 398-408.

[50] X. Li, D. Diao, B. Bhushan, Fracture mechanisms of thin amorphous carbon films in nanoindentation, Acta Mater. 45 (11) (1997) 4453-4461.

[51] M.D. Michel, L.V. Muhlen, C.A. Achete, C.M. Lepienski, Fracture toughness, hardness and elastic modulus of hydrogenated amorphous carbon films deposited by chemical vapor deposition, Thin Solid Films 496 (2) (2006) $481-488$.

[52] H. Miyazaki, Y. Yoshizawa, Refined measurements of indentation fracture resistance of alumina using powerful optical microscopy, Ceram. Int. 40 (2) (2014) 2777-2783. 